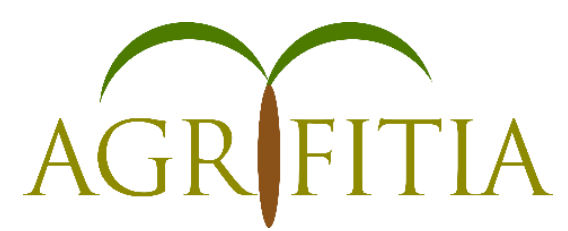

Journal Agrifitia. Vol. 1, No. 2, September 2021

Journal home page: https://jurnal.instiperjogja.ac.id/index.php/AFT

\title{
PERAN PERUSAHAAN DALAM MENINGKATKAN KUALITAS HIDUP KARYAWAN di PT. TRI BAKTI SARIMAS
}

\author{
Gantara Tino Pasomba ${ }^{1}$, Purwadi ${ }^{1}$, Fitri Kurniawati ${ }^{1}$ \\ ${ }^{1}$ Jurusan Ekonomi Pertanian, Fakultas Pertanian, INSTIPER Yogyakarta
}

\begin{abstract}
This research on the role of the company in improving the quality of life of employees was carried out at PT. Tri Bakti Sarimas, in Sei Pendulangan AFD II Pangkalan Village, Kuantan Mudik District, Kuantan Singingi Regency, Riau. This study aims to determine the role of the company in improving the quality of life of its employees and to determine the average income of employees in improving the quality of life of employees. The method used is descriptive analysis by collecting data through interviews using questionnaires. Samples were obtained by Simple Random Sampling with a total sample of 60 people. The results of this study indicate that the company's role in improving the quality of life of employees so that employees who work in the company can live in prosperity and they can work with high loyalty to the company. And the average income earned by employees is Rp. 3,375,000 this amount has exceeded the basic salary of the company so that they can improve their quality of life
\end{abstract}

Keywords : Company Role, Employee Quality of Life 


\section{PENDAHULUAN}

Perusahaan dan karyawan itu sangatlah saling membutuhkan, karyawan sangatlah dibutuhkan oleh perusahaan untuk membantu mencapai tujuan perusahaan tersebut, karyawan pun tidak dapat menunjang kesejahteraan hidupnya apabila tidak ada perusahaan untuk mencari nafkah.Perusahaan pun harus memiliki strategi untuk mengelola sumber daya manusia yaitu dengan cara pemeliharaan karyawan dengan baik.. Agara para karyawan dapat semangat dalam bekerja, meningkatkan prestasi kerja,berdisiplin tinggi, dan selalu loyal dalammenunjang tujuan perusahaan makaperusahaan memperhatikan kesejahteraan karyawannya. Dan perusahaan membentukprogram kesejahteraan karyawan.

Sumber daya manusia merupakan faktor yang sangat berharga, maka perusahaan bertanggungjawab untuk memelihara kualitas kehidupan kerja dan membina tenaga kerja agar bersedia memberikan kontribusinya secara optimal untuk mencapai tujuan perusahaan (Pruijt, Hans. 2003). Ada beberapa dimensi yang ada di dalam kualitas kehidupan kerja yang diharapkan dapat meningkatkan kualitas sumber daya manusia yaitu berpartisipasi dalam pemecahan masalah, sistem imbalan yang inovatif, perbaikan lingkungan kerja dan restrukturisasi kerja. Kualitas kehidupan kerja merupakan masalah tama yang patut mendapat perhatian dari perusahaan. Dengan adanya kompensasi berpengaruh terhadap kualitas hidup karyawan (Mayangsari, Hadi, dan Hidayat 2014). Menurut Ummi Mardiah dan Simatupang (2020), Inovasi dan adanya peran perusahaan juga turut berpengaruh terhadap kualitas hidup karyawan. Organisasi yang semakin baik maka akan mempengaruhi kinerja kayawan semakin baik (Suzanna 2017).

Adanya kualitas kehidupan kerja jugamenumbuhkan keinginan para karyawan untuk tetap tinggal dan bertahan di dalam organisasi. Hal itu juga dapat dinilai bahwa karyawan menunjukkan rasa puasnyaterhadap perlakuan perusahaan terhadap dirinya. Kepuasan dapat dipandang sebagai pernyataan positif hasil dari penilaian para karyawan terhadap apa yang telah dilakukan oleh perusahaan/organisasi kepada parakaryawannya. Kepuasan karyawan akan dapat menumbuhkan komitmen dan loyalitas karyawan. Berdasarkan rumsuan masalah diatas maka tujuan dari penelitian adalah untuk mengetahui adanya hubungan positif antara praktek kualitas kehidupan kerja dengan komitmen dan kinerja karyawan.

\section{METODOLOGI}

Metode yang digunakan dalam penelitian ini adalah metode deskriftif, yaitu menggambarkan dan menginterprestasikan objek sesuai adanya atau menjelaskan tentang fenomena yang terjadi disekitar objek penelitian. Pemilihan lokasi penilitian ini dilakukan secara purposive sampling yaitu teknik pengambilan lokasi penelitian dengan cara sengaja (Sugiyono 2016). Penelitian ini dilaksanakan pada bulan Agustus sampai September 2019. 
pengambilan sampel karyawan yang dilakukan dengan cara Simple Random Sampling dimana pengambilan karyawan sampel dari populasi yang ada dilakukan secara acak tanpa memperhatikan strata yang ada pada populasi tersebut. Cara pengambilan sampel dengan cara acak yang diambil berjumlah 60 orang. Data yang digunakan dalam penelitian ini adalah terdiri dari data primer dan data sekunder.

\section{HASIL DAN PEMBAHASAN}

\section{A. Deskripsi Profil Responden}

1. Usia

Berdasarkan hasil yang diperoleh, distribusi umur karyawan di PT. Tri Bakti Sarimas berada antara 20 sampai dengan 60 tahun.

Tabel 1. Usia Karyawan PT. Tri BaktiSarimas

\begin{tabular}{ccc}
\hline Usia (tahun) & Jumlah & Persentase \\
\hline $20-30$ & 10 & 16,7 \\
$31-40$ & 44 & 73,3 \\
$41-50$ & 5 & 8,3 \\
$51-60$ & 1 & 1,7 \\
Total & 60 & 100 \\
\hline
\end{tabular}

Sumber : Data primer (diolah)

Pada Tabel.3.1 menunjukan bahwa karyawan yang mendominasi adalah pada usia31 sampai 40 tahun yaitu sebanyak 44 orang atau 73,3 persen. Sedangkan usia 20 sampai 30 tahun sebanyak 10 orang atau 16,7 persen, pada usia 41 sampai 50 tahun sebanyak 5 orang atau 8,3 persen, dan pada usia 51 sampai60 sebanyak 1 orang atau 1,7 persen.

\section{Tingkat Pendidikan}

Tingkat pendidikan adalah pendidikan yang di peroleh secara formal dan berhasil ditamatkan sebagai pendidikan terakhir oleh karyawan PT. Tri Bakti Sarimas. Tingkat pendidikan para karyawan yang menjadi responden cukup beragam mulai dari SD, SMP hingga SMA. Jumlah dan pesentase berdasarkan tingkat pendidikan dapat dilihatpada Tabel .2

Tabel 2. Tingkat Pendidikan Karyawan diPT. Tri Bakti Sarimas

\begin{tabular}{ccc}
\hline Tingkan Pendidikan & Jumlah & Persentase \\
\hline SD & 14 & 23,3 \\
SMP & 33 & 55 \\
SMA & 13 & 21,7 \\
\hline Total & 60 & 100
\end{tabular}

Sumber : Data Primer (diolah) 
Berdasarkan Tabel 3.2 diatas dapatdilihat bahwa tingkat pendidikan karyawan yang mendominasi di PT Tri Bakti Sarimasadalah tingkat pendidikan SMP yaitu sebanyak 33 orang dengan persentase 55 persen. Sedangkan tingkat pendidikan SMA yaitu sebanyak 13 orang dengan persentase 21,7 persen dan tingkat pendidikan SD yaitu sebanyak 14 orang atau 23,3 persen.

\section{B. Analisis Pendapatan Dan Pengeluaran Karyawan Di PT. TRI BAKTI SARIMAS 1. Pendapatan Karyawan \\ a. Pendapatan Karyawan}

Tabel 3. Pendapatan karyawan PT. TriBakti Sarimas

\begin{tabular}{ccc}
\hline Pendapatan & Jumlah & Persentase \\
\hline $1.500 .00-2.000 .000 \mathrm{jt}$ & 1 & 1,7 \\
$2.500 .000-3.000 .000 \mathrm{jt}$ & 24 & 40 \\
$3.500 .000-4.000 .000 \mathrm{jt}$ & 27 & 45 \\
$>4.500 .000 \mathrm{jt}$ & 8 & 13,3 \\
Rata - Rata Pendapatan : Rp 3.375.000 & &
\end{tabular}

Sumber : Data Primer (diolah)

Berdasarkan tabel 3 di atas pendapatan terkecil 1.500.000 - 2.000.000 juta ada 1 orang dan yang mendominasi ada di pendapatan 3.500.000- 4.000.000 juta dengan jumlah 27 orang.Untuk UMP diperushaan tersebut adalah 2.800 .000 juta jadi dapat disimpulkan 1.500 .000 - 2.000.000 juta hasil dari karyawan yangbekerja tidak memenuhi target sedangkan karyawan dengan pendapatan 3.000.0000-5.000.000 juta itu dipengaruhi oleh premi karena karyawan tersebut bekerja melebihi target. b.Pengaruh Masa Kerja TerhadapPendapatan

Tabel 4. Pengaruh Masa Kerja Terhadap Pendapatan Di PT. Tri Bakti Sarimas

\begin{tabular}{lcc}
\hline Masa Kerja & Jumlah & $\begin{array}{l}\text { Rata - Rata } \\
\text { Pendapatan }\end{array}$ \\
\hline 4 bulan -2 tahun & 35 & Rp 2.980 .000 \\
2,5 tahun -5 tahun & 10 & Rp 3.474.286 \\
6 tahun - 9tahun & 8 & Rp 3.137.500 \\
10 tahun -14 tahun & 7 & Rp 3.714.286 \\
\hline
\end{tabular}

Sumber : Data Primer (diolah)

118 | Peran perusahaan dalam meningkatkan kualitas..... ---- Gantara Tino Pasomba, dkk. 
Berdasarkan tabel 4 dimana 2,5tahun - 5 tahun pendapatan rata-rata $\mathrm{Rp} 3.474 .286$ sedangkan pada masa kerja 6 tahun - 9 tahun itu pendapatan rata-ratanya Rp 3.137.500. Jadi dapat disimpulkan bahwa masa kerja tidak mempengaruhi pendapatan melainkan dengan hasil kinerjakaryawan dalam bentuk premi.

c. Pengaruh Umur Terhadap Pendapatan

Tabel 5. Pengaruh Umur Terhadap Pendapatan Di PT. Tri Bakti Sarimas

\begin{tabular}{ccc}
\hline Umur & Jumlah & $\begin{array}{c}\text { Rata - Rata } \\
\text { Pendapatan }\end{array}$ \\
\hline 22 tahun -35 tahun & 30 & Rp 3.280.000 \\
36 tahun -45 tahun & 28 & Rp 3.517.857 \\
46 tahun -55 tahun & 2 & Rp 2.800.000
\end{tabular}

Sumber : Data Primer (diolah)

Berdasarkan tabel 5 dimana umur 36 th-45 th pendapatan rata-rata $\mathrm{Rp}$. 3.517.857 sedangkan pada umur 46 thn - 55 thn itu pendapatan rata-rata nya $R p 2.800 .000$ dan untuk umur 22 thn -35 thn pendapatan rata-rata $\mathrm{Rp} 3.280 .000$. Jadi dapat disimpulkan bahwa umur mempengaruhi pendapatan dikarenakan usia lebih muda kinerja lebih produktif sedangkan yang sudah lanjut usia kinerja sudah mulai menurun.

\section{Pengeluaran Karyawan}

Tabel 7. Pengeluaran KaryawanBerdasarkan Komponen

\begin{tabular}{cll}
\hline No & Pengeluaran/Bulan & Rata-Rata \\
\hline 1 & Konsumsi & Rp 1.356.667 \\
2 & Sandang & Rp 902.500 \\
3 & Komunikasi & Rp 273.333 \\
4 & Sekolah Anak & Rp 563.333 \\
5 & Bahan Bakar Kendaraan Pribadi & Rp 251.667 \\
\hline & Total & Rp3.347.500 \\
\hline
\end{tabular}

Sumber : Data Primer (diolah)

Pengeluaran berdasarkan konsumsi yang dimaksud yaitu pengeluaran yang digunakan untuk membeli kebutuhanbahan pangan sehari-hari. Pengeluaran berdasarkan sandang yang dimaksud yaitu pengeluaran yang digunakan untuk membeli pakaian dan lain-lain. Pengeluaran berdasarkan komunikasi yangdimaksud yaitu pengeluaran yang digunakan untuk membeli pulsa dan paket internet untuk berkomunikasi dengan keluarga dan kerabat jauh. Pengeluaran berdasarkan biaya sekolah atau pendidikan anak yang dimaksud yaitu pengeluaran yang digunakan untuk memberi uang saku anak dan untuk 
membeli keperluan sekolah seperti alat tulis dan buku pelajaran. Pengeluaran berdasarkan biaya bahan bakar kendaraan pibadi yangdimaksud yaitu pengeluaran yangdigunakan untuk membeli bahan bakar kendaraan pribadi yang digunakan untuk sehari-hari.

\section{Fasilitas-Fasilitas Yang DiberikanPerusahaan}

a. Fasilitas Kantin Yang DisediakanPerusahaan

Kantin disediakan oleh perusahaan itu ada jadi para karyawan dapat beristirahat apabila telah menyelesaikan perkerjaan sehingga mereka tak perlu mencari tempat lain untuk beristirahat. Untuk kondisi kantin disana cukuplah besar sehingga banyak karyawan yangdapat beristirahat sambil bercengkramadengan karyawan lainnya dan makanan yang dijual pun banyak dari jajanan ringan, kopi dan para karyawan bisa membeli nasi dan lauk pauk sehingga karyawan yang tidak membawa bekal bisa makan dikantin tersebut. Makanan yang disediakan cukup megandung 4 sehat 5 sempurna sehingga para karyawan tidak perlu mengkhawatirkan untuk makan dikantin tersebut Kantin akan buka pada pukul 08.00-14.00, disana para karyawan boleh bayar makanan atau minuman bisa pada saat gajian dalam artian mereka bisa membuat bon dikantin tersebut tatapi pihak kantin hanya berani memberi bon kepada karyawan yang sudah dikenal lama dan bekerja lama di perusahaan tersebut dan untuk karyawan yang baru- baru masih belum berani memberi bon kepada mereka.

b.Tempat Ibadah Yang Disediakan Oleh Perusahaan.

Perusahaan pun menyediakan tempat ibadah seperti masjid dan gereja untuk para karyawan beribadah. Perlengkapan untuk beribadahnya pun lengkap sehingga para karyawan dapatberibadah dengan nyaman dan karyawan dapat sehat secara rohani. Sebuahmusolah disana dibangun disetiapafdelinng dan untuk masjid sendiri dibangun didekat kantor perusahaan, kemudian untuk gereja sendiri dibangun didua tempat yang berbeda untuk gereja HKBP sendiri dibangun daerah centralatau dekat kebun kelapa hybrida dan gereja umum nya sendiri dibangun di afdeling 3 lama. Para karyawan disana bisa membuat kegiatan keagaman sesuai keyakinan masing-masing misal acara besar maulid nabi dan lain-lain begitujuga acara umat kristen seperti perayaan paskah, natal dan lain- lain nya. Untuk anak-anak yang beragama islam pun disana bisa belajar mengaji dimusolah sehingga anak-anak memahami agama mereka dengan benar dan untuk anakanak yang beragama kristen disana juga bisa melaksanakan sekolah minggu yang diadakan digereja yang ada di afdeling 3 maksud dari sekolah minggu ini adalah dimana anak-anak tersebut mempelajariagama lebih dalam lagi. 
c. Bangunan Sekolah Untuk Anak-AnakPara Karyawan.

Didekat perusahaan adapun didirikan nya sekolah untuk para anakkaryawan besekolah sehingga para karyawan tak memikirkan dimana anaknya untuk menimba ilmu. Karena bagi karyawan sekolah itu sangat pentingbagi anak-anak mereka untuk mengenyam pendidikan. Dan kendaraan untuk anak karyawan berangkat sekolah pun disediakan sehingga para orang tua tidak perlu mengantar anak mereka kesekolah dan tidak perlu menjemput, untuk penjemputan anak-anak sekolah stand by pada pukul 05.30. Untuk jarak tempuh kesekolahnya pun butuh waktu 15-20 menit itu tergantung tempat anak itu tinggal karena sekolah didirikan didekat kantor perusahaan. Bangunan pun merupakan bangun permanen sehingga para murid bisa belajar dengan baik, untuk bangunan sekolah SD danSMP itu ada didalam areal kebun sedangkan untuk SMK itu dibangun tidak jauh dari kebun. Dalam proses belajar nya untuk SD mereka mulai belajar pada pukul 07.00-12.00, untuk SMP dan SMK itu dari jam 07.00-14.00. Fasilitas disekolah pun cukup lengkap yaitu ada perpustakaan untuk para murid membaca buku, lapangan untuk mereka berolahragaa dan lain-lain.

d.Tempat Berobat Dibangun DiareaPerusahaan.

Diarea perusahaan pun ada tempat berobat yang disediakan berupa klinik yang dibangun untuk para karyawan. Halini menunjukan bahwa pelayanankesehatan yang disediakan perusahaan sangat membantu karyawan dalam menangani kesehatan para karyawan. Tetapi klinik yang dibangun perusahaan terlalu jauh untuk ditempuh oleh karyawan sehingga perusahaan harusnya membangun klinik tambahan yang tidak jauh dari perumahan karyawan sehingga karyawan tak perlu menempuh jarak yang jauh untuk berobat diklinik. Danapabila ada karyawan terluka parah akan dibuatkan surat rujukan kerumah sakit yang lebih besar, untuk kendaraan mengantar orang sakit pun perusahaan menyediakan mobil ambulan sehingga mereka dapat langsung mengantar karyawan sakit parah langsung kerumah sakit besar sehingga cepat ditangani olehpihak rumah sakit. Jadi untuk peralatan diklinik tersebut lengkap untuk mengobati karyawan yang sakit nyatidak terlalu parah.

e.Asuransi Kesehatan Dan Kecelakaan Kerja Yang Diberikan Kepada Karyawan.

Adapun asuransi kesehatan dan kecelakaan kerja yang diberikan untuk para karyawan dari perusahaan yaitu BPJS sehingga karyawan tidak perlu khawatir dengan kesehatan mereka dalam bekerja di perusahaan tersebut. Hal ini menunjukan bahwa asuransi yang disediakan perusahaan sangat membantu karyawan sehingga mereka merasa terjamin dengan adanya asuransi. Jadi apabila ada karyawan yang teruka parah dan kemudian harus dirujuk kerumah sakit besar untuk biayanya nanti akan dipotong dari asuransi mereka. Asuransi meninggal pun diberikan kepada karyawan yang meninggal kepada keluarga yang bersangkutan. 
f. Perumahan Yang Disediakan PerusahaanUntuk Karyawan

Pihak perusahaan telahmembangun perumahan untuk parakaryawan sehingga karyawan tak perlu lagi mencari tempat tinggal apabila bekerja diperusahaan tersebut. Hal ini menunjukan bahwa perumahan yang disediakan perusahaan sangat membantu karyawan untuk bertempat tinggal diperusahaan tersebut terutama bagi para karyawan yang merantau. Bangunan perumahannya pun permanen sehinggapara karyawan dapat tinggal denganaman, untuk perumahan yang didekat aliran sungai itu biasa nya bisa terkena banjir apabila hujan terus menerus turun sehingga membuat air sungai meluap sampai naik kedaerah perumahan. Untukmengatasinya agar air tidak masuk kerumah mereka pun membuat blok dari karung yang diisi pasir dan diletakkandidekat perumahan.

g. Transportasi Untuk Karyawan Perusahaan pun menyediakan

Transportasi untuk para karyawan berangkat bekerja dilapangan berupa truk sehingga para karyawan lapangantak perlu khawatir untuk berangkat bekerja. Hal ini menunjukan bahwa transportasi yang disediakan perusahaan sangat membantu karyawan dalam bekerja. Transportasi untuk mengantar para karyawan untuk bekerja akan menjemput para karyawan jam 05.30 danpara karyawan akan diantar ke tempat mereka bekerja sesuai blok-blok yang sudah ditentukan oleh mandor mereka,dan untuk penjemput pulang akan dijemput pada pukul 15.00.

h.Tempat Olahraga Untuk Para Karyawan.

Pihak perusahaan pun membuatlapangan olahraga yang dapat digunakan para karyawan untuk berolahraga padahari libur sehingga mereka dapat sehat secara jasmani. Hal ini menunjukan bahwa lapangan olahraga yang disediakan perusahaan sangat membantu karyawan dalam kegiatan olahraga. Dilapangan tersebut kita bisa berolahraga sepuasnya bisa bermain sepak bola dan juga bisa lari dilapangan tersebut, tak jarang pula para karyawan disana membuat pertandingan sepak bolaantara afdelinng atau antar estate dengan cara ini para karyawan mempererat kekeluaragaan dan silaturahmi sehingga tidak ada bentrokan antar karyawan. Tetapi sudah hampir 1 tahun sudah tidak ada lagi pertandingan yang mereka buat dikarenkan lapangan olahraga yangdisediakan sudah mulai rusak dan para karyawan pun berharap dari pihak perusahaan untuk memperbaiki lapangantersebut. Dengan demikian parakaryawan membuat lapangan kecil untuk mereka bisa berolahraga.

Hasil yang diperoleh untuk pendapatan yang karyawan peroleh itu dari gaji pokok dan premi, UMP disana sebesar Rp 3.045.450 dan rata-rata para karyawan bekerja disana mendapatkan gaji yang melebehi UMP dengan rata-rata gaji yang diperoleh para karyawan $\mathrm{Rp}$ 3.375.000, apabila karyawan bekerja dengan giat sehingga melebihi target akan mendapatkan premi sehingga gaji mereka tinggi. Jadi para karyawan dapat meningkatkan kualitas hidup dengan tentunya ada peranan perushaan dialam nya. 
Dalam analisis pengeluaran karyawan dapat dilihat bahwa ada 5 pengelompokan pengeluaran :

1. Pengeluaran Untuk Konsumsi

2. Pengeluaran Untuk Sandang

3. Pengeluaran Untuk Biaya Komunikasi

4. Pengeluaran Untuk Biaya Sekolah anak

5. Pengeluaran Untuk Biaya BahanBakar Kendaraan Pribadi

Fasilitas - fasilitas yang disediakan oleh perusahaan itu sudah cukup memadai dan sudah banyak membantu para karyawan disana untuk memenuhi kebutuhan sandang, pangan,papan mereka. Dan dimana arti dari kualitas hidup adalah kualitas yang dirasakan dalam kehidupan sehari-hari individu, yaitu suatu penilaian atas kesejahteraan mereka atau ketiadaannya. Hal ini mencakup seluruh aspek emosi, sosial, dan fisik dalam kehidupan individu (Wikipedia, 2020). Sehingga para karyawan disana dapat hidup dengan sejahtera sekaligus meningkatkan kualitas hidup karyawan diperusahaan tersebut. Dengan demikian adanya peran perusahaan dalam meningkatkan kualitas hidupkaryawan dengan cara tidak langsung sehingga para karyawan dapat hidupdengan sejahtera dengan semua apa yang telah diberikan oleh perusahaan dengan begitupun karyawan dapat lebih produktiv dan loyal bekerja di perusahaan tersebut sehingga dapat tercapai nya tujuan perusahaan tersebut

\section{KESIMPULAN}

1. Adanya peran perusahaan dalam meningkatkan kualitas hidup karyawan sehinngga para karyawan yang bekerja di perusahaan tersebut dapat hidup dengan sejahtera dan mereka dapat bekerja dengan loyalitas tinggi kepada perusahaan.

2. Jumlah pendapatan rata-rata yang diperoleh para karyawan yaitu Rp. 3,375,000 jumlah tersebut telah melebihi gaji pokok dari perusahaan tersebut sehingga mereka dapat meningktkan kualitas hidup.

\section{DAFTAR PUSTAKA}

Pruijt, Hans. (2003). Performance and Quality of Work Life, Journal of Organizational ChangeManagement, Vol. 13, p.389-400.

Mayangsari, Devita, Sudharto P. Hadi, and Wahyu Hidayat. 2014. "Pengaruh Peran Total Quality Management Dan Kompensasi Terhadap Kualitas Sumber Daya Manusia PT. Djarum (Studi Kasus Pada Pabrik BL 53 Kudus)." Diponegoro Journal of Social and Politic 1-8.

Sugiyono. 2016. Metode Penelitian Kuantitatif, Kualitatif, R\&D. Bandung: ALFabeta. 
Suzanna, Anna. 2017. "Pengaruh Organizational Citizenship Behavior (OCB) Terhadap Kinerja Karyawan Pada PT Taspen (PERSERO) Kantor Cabang Cirebon." Jurnal Logika XIX(1):42-50.

Ummi Mardiah, and Pandapotan Simatupang. 2020. "Pengaruh Peran Dan Inovasi Terhadap Kinerja Karyawan Di Ptpn Iv Unit Kebun Marihat." Manajemen : Jurnal Ekonomi 2(2):12433. doi: 10.36985/manajemen.v2i2.358. 